\title{
Correction to: An Examination of Crisis Intervention Teams in Rural Jurisdictions
}

\author{
Michele P. Bratina ${ }^{1}\left(\mathbb{D} \cdot\right.$ Jacqueline A. Carsello ${ }^{1} \cdot$ Kelly M. Carrero $^{2}\left(\mathbb{D} \cdot\right.$ Michael E. Antonio $^{1}(\mathbb{C}$
}

Published online: 9 March 2021

๑) Springer Science+Business Media, LLC, part of Springer Nature 2021

\section{Correction to: Community Mental Health Journal https://doi.org/10.1007/s10597-021-00797-7}

The original version of this article unfortunately contained an error in "Abstract" and "Results" sections.

In Abstract, the word "effect" should read as "affect" and the correct sentence is as follows:

Rural-specific impediments affect each aspect and member of Crisis Intervention Teams in rural jurisdictions.

In Results section, under "Time and Money", the below sentence should be removed:

A participant who is the CIT coordinator for a county that employed mostly part-time officers stated:
The original article has been corrected.

Publisher's Note Springer Nature remains neutral with regard to jurisdictional claims in published maps and institutional affiliations.

The original article can be found online at https://doi.org/10.1007/ s10597-021-00797-7.

Michele P. Bratina

MBratina@wcupa.edu

1 Department of Criminal Justice, West Chester University of Pennsylvania, West Chester, PA, USA

2 Department of Psychology \& Special Education, Texas A\&M University, Commerce, TX, USA 